\title{
Naming and contingency: the type method of biological taxonomy
}

\author{
Joeri Witteveen
}

Biology \& Philosophy*

\begin{abstract}
Biological taxonomists rely on the so-called 'type method' to regulate taxonomic nomenclature. For each newfound taxon, they lay down a 'type specimen' that carries with it the name of the taxon it belongs to. Even if a taxon's circumscription is unknown and/or subject to change, it remains a necessary truth that the taxon's type specimen falls within its boundaries. Philosophers have noted some time ago that this naming practice is in line with the causal theory of reference and its central notion of rigid designation: a type specimen fixes the reference of a taxon name without defining it. Recently, however, this consensus has come under pressure in the pages of this journal. In a series of articles by Alex Levine, Joseph LaPorte, and Matthew Haber, it has been argued that type specimens belong only contingently to their species, and that this may bode problems for the relation between type method and causal theory. I will argue that this 'contingency debate' is a debate gone wrong, and that none of the arguments in defense of contingency withstand scrutiny. Taxonomic naming is not out of step with the causal theory, but conforms to it. However, I will also argue that this observation is itself in need of further explanation, since application of the type method in taxonomic practice is plagued by errors and ambiguities that threaten it with breaking down. Thus, the real question becomes why taxonomic naming conforms to the causal theory in the first place. I will show that the answer lies in the embedding of the type method into elaborate codes of nomenclature.
\end{abstract}

${ }^{*}$ This version is identical to the published version, available at http://dx.doi.org/10. 1007/s10539-014-9459-6 Earlier versions of this paper were presented at ISHPSSB 2013 in Montpellier, PBUK 2014 in Cambridge, and Utrecht University. I am grateful to these audiences for helpful feedback. Two anonymous reviewers, Matt Haber, Michael Devitt, and (especially) Kim Sterelny provided many thoughtful comments on earlier versions of the manuscript. 


\section{Introduction}

Biological taxonomists rely on the so-called 'type method' to regulate taxonomic nomenclature. When they name a newfound taxon, they anchor the new taxon name to a name-bearing sample of that taxon, its 'type specimen'. A type specimen need not be a representative or 'typical' exemplar of its taxon. In fact, type specimens are typically not typical, since the discoverer of a new taxon is usually unfamiliar with the full range of variation within that taxon. $]^{1}$ The only role type specimens serve is that of fixing the reference of taxon names. They are stable anchors for the application of taxon names in the face of changing views about taxon boundaries.

Starting with David Hull (1976, 1982, 1988), philosophers have noted that this method of naming conforms to the Kripke-Putnam causal theory of reference (Kripke, 1980; Putnam, 1975). Type specimens are laid down in baptismal ceremonies, and the names they carry get passed on in anaphoric, reference-preserving chains of communication. Even if current classifications turn out to be wholly erroneous, we can still know with certainty about any type specimen that the name it carries designates the taxon it belongs to. Taxon names carried by type specimens are rigid designators.

Hull's observations have since been echoed by many others, and have become something of an orthodoxy in the philosophy of taxonomy (e.g. Bolton, 1996; Ereshefsky, 2004, 2007; Mayr, 1989; Stanford and Kitcher, 2000). That is, until a stimulating article by Levine (2001) ignited renewed discussion about the philosophical status of the type method.

Levine's article kicked off what I will refer to as the 'contingency debate' in the philosophy of taxonomy. Levine argues that the type method is irreconcilable with a widely embraced thesis that was also promoted by Hull: the thesis that species are individuals. According to the type method, a type specimen necessarily belongs to the species it anchors the name of. But the species-as-individuals thesis tells us that all specimens belong to their species only contingently. It thus appears, paradoxically, that type specimens belong to their species both necessarily and contingently. This puts pressure on the kinship between taxonomic naming and the causal theory of reference - or so Levine argues.

LaPorte (2003) and Haber (2012) have taken issue with Levine's argument. LaPorte argues that although the relation between type specimens and species-individuals is contingent in some sense, the relevant notion of contingency does not conflict with the received interpretation of the type method.

\footnotetext{
${ }^{1}$ The modern-day type method should therefore not be confused with the Method of Type articulated by Whewell (1840). On the latter method, a type-element was defined as an exemplar that served to explore a taxon's boundaries. The fascinating change in the meaning of 'type' from Method of Type to type method is traced in (Witteveen, in progress).
} 
Haber in his turn has challenged the arguments from LaPorte and Levine. In Haber's view, both earlier accounts fall into the trap of discussing the type method 'in the abstract' only, with help of toy examples. They thereby conceal the complications of real-life taxonomic naming practices, and abstract away from the embedding of the type method in elaborate codes of nomenclature. Haber considers this a mistake, since attending to contextual factors reveals another dimension of contingency in the relation between type specimens and their species. This sort of contingency poses a threat to rigid designation, and thus introduces new complications for the relation between type method and causal theory.

In this paper, I aim to show that the contingency debate is a debate gone wrong. First, because the debate involves a number of misunderstanding by the participants of each others' positions. Most crucially, I will show that LaPorte and Haber misunderstand Levine's actual worries about contingency, and therefore fail to tackle his paradox. Secondly, and more importantly, I will argue that none of their arguments in defense of contingency go through; there is no sense in which type specimens belong contingently to the species they name. This means that taxonomic naming can be accounted for on the causal theory after all.

Nevertheless, and in spite of these errors, the contingency debate offers a valuable lead towards enhancing philosophical understanding of the type method. The lead is Haber's insistence to examine the type method in situ, and by attending to its embedding in nomenclatural codes. I will argue that it is indeed crucial to understand the nature of this embedding, but not because doing so reveals that the received understanding of the type method collapses (as Haber thinks). On the contrary, I will show that these nomenclatural codes enable us to see how the type method is made to work in taxonomic practice. They reveal how the type method is insulated from practical errors and ambiguities that would otherwise cause it to break down.

This paper is composed of three parts and a brief conclusion. In the first part, I will provide an overview of the contingency debate and spell out the arguments that have been brought forward (Section 2). In the second part, I will critically examine the course this debate has taken, and the arguments that have been offered. Here I will compare and contrast the different accounts of contingency that have been defended, and argue that none of them withstand scrutiny (Section 3). In the final part, I will take a closer look at actual naming practices, and at the embedding of the type method in nomenclatural codes. Here I raise and answer the question why the type method can work at all in the face of so much contingency surrounding it (Section 4). 


\section{Naming, necessity, and contingency}

\subsection{Levine's paradox}

The paradox which Levine (2001) considers to arise in modern biological taxonomy, emerges from the prior acceptance of two prima facie uncontroversial theses about the type method and about biological species. I will call these the designation thesis and the contingency thesis, respectively. They can be summarized as follows:

Designation thesis: The type specimen that anchors the taxon name ' $S$ ' belongs of necessity to the taxon $S$ that is designated by ' $\mathrm{S}$ '. It is impossible for a type specimen not to belong to the taxon for which it carries the name.

Contingency thesis: The relation between any organism $o$ and the species $S$ it belongs to is contingent. None of the specimens that happen to belong to a species $S$ belong to it of necessity.

Levine notes that the designation thesis is entailed by Hull's (1982) interpretation of the type method. He takes the contingency thesis to be entailed by the view that species are individuals (or historical entities).

According to Levine, it is easy to see that a paradox ensues from accepting both the designation thesis and the contingency thesis. Since the type specimen of $S$ just is an organism $o$ of $S$, we are forced to conclude that it belongs to its species of necessity and contingently. This is surely paradoxical. "We can only conclude that, qua organism, the type specimen belongs to its respective species contingently, while qua type specimen, it belongs necessarily. But this statement merely codifies the contradiction without resolving it." (ibid., p. 334).

\subsection{LaPorte's solution}

LaPorte (2003) offers a lucid rebuttal to Levine. According to LaPorte, the paradox Levine raises is only apparent. It results from Levine's failure to distinguish between two different (and compatible) modal claims about the relation between species and their type specimens.

LaPorte's rebuttal can be sketched as a two-step argument. First, he highlights a modal difference between the designation thesis and the contingency thesis. Next, he repeats the step that Levine argues leads to a paradoxical conclusion: he runs the contingency thesis for the type specimen of $S$.

To bring out the modal distinction, LaPorte starts by rephrasing the designation thesis as follows: "Necessarily, any species with a type specimen contains its type specimen." This sentence expresses a de dicto proposition. It states that in any possible world - in any counterfactual situation - in 
which a specimen is baptized as the type specimen of a species $S$, it belongs with necessity to $S$. This, LaPorte argues, is indeed true. The contingency thesis, on the other hand, expresses a de re claim. It tells us about something that obtains across possible worlds, regardless of our naming ceremonies. The contingency thesis states that it is contingent de re that a species $S$ contains the specimen $o$ it contains in the actual world, since there are possible worlds in which $S$ exists but $o$ was never born.

With this distinction between de dicto necessity and de re contingency in hand, LaPorte evaluates the implications of the contingency thesis for type specimens. He considers that since the type specimen $x$ of species $S$ is a specimen $o$ of $S$, it follows that $x$ belongs to $S$ contingently de re. Thus, LaPorte concludes, it is contingent de re that a species with a type specimen contains its type specimen. In other words, the de re sentence "Any species with a type specimen necessarily contains its type specimen" is false.

When we put this de re sentence next to the earlier de dicto sentence, we see that there is nothing paradoxical about a type specimen belonging to its species of necessity and contingently. We just need to bring out that any given type specimen belongs to its species with de dicto necessity and contingently de re.

\subsection{Haber's complication}

Haber (2012) agrees that LaPorte's "satisfying and elegant" distinction between modalities proves Levine wrong. There is no contingency paradox. Nevertheless, Haber concludes about LaPorte's argument that "in a deeply important sense it goes wrong" (ibid., p. 773). The problem is that the designation thesis - even on LaPorte's rendering - is true in the abstract only. Actual taxonomic practice introduces complications that undermine the designation thesis. It reveals that a species can have a type specimen without containing it: "Type specimens do not belong of necessity to the species they designate."

Haber arrives at this verdict by analyzing a fascinating case study from zoological taxonomy. He takes this case study to show that a type specimen can be misidentified; it can be found not to belong to the taxon for which it was laid down as name-bearer. For purposes of later discussion and analysis, I will go over this case study in quite some detail.

In the late 1990s, a dispute arose over the naming of two Californian subspecies of the Common Garter Snake species, Thamnophis sirtalis. The dispute concerned the San Francisco Garter Snake, T. s. tetrataenia, which only lives on the San Francisco peninsula, and the California Red-Sided Garter Snake, T. s. infernalis, which can be found along much of the California coast (Figure 11a). In 1995, taxonomists Boundy and Rossman (hereafter: B\&R) made a surprising discovery about the naming of these two subspecies. In 


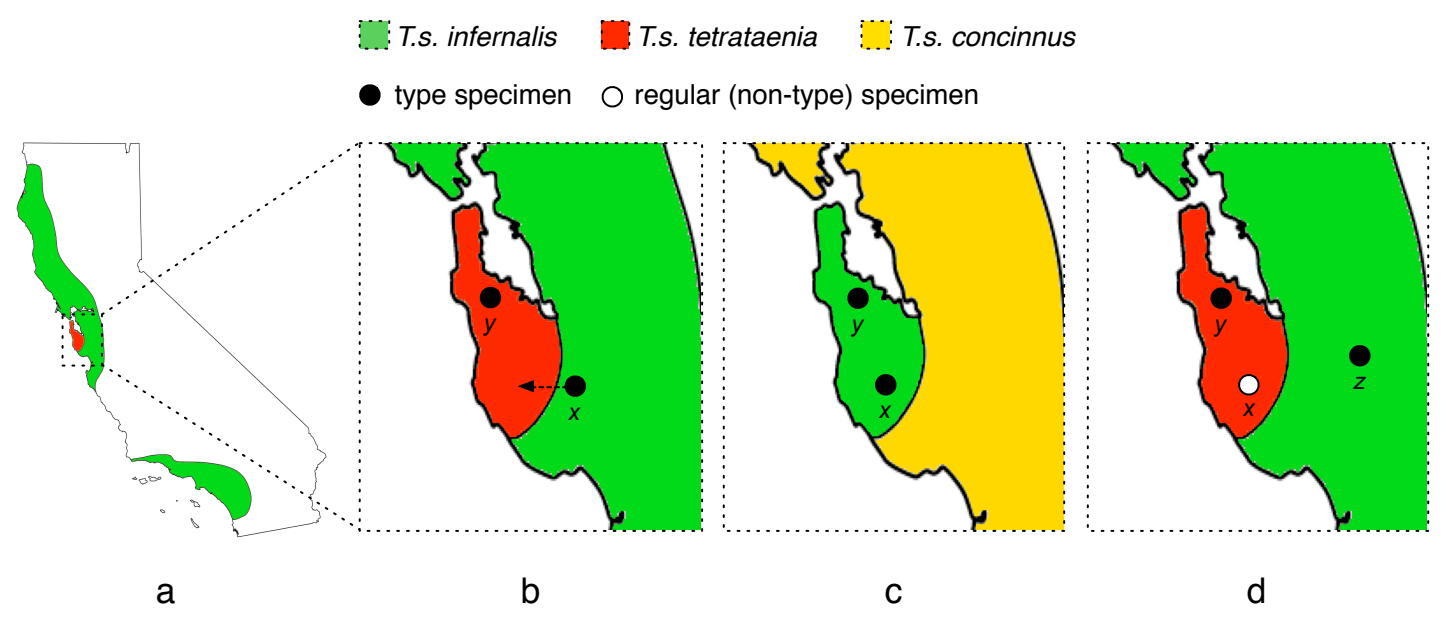

Figure 1: (a) The ranges of T. s. infernalis and T. s. tetrataenia in California, as hypothesized before 1995. The infernalis subspecies was considered to be located along most of the California coast, and the range of tetrataenia was restricted to the San Francisco peninsula; (b) The filled dots indicate what, before 1995, were thought to be the collection locations of type specimen $x$ for the name 'infernalis' and of type specimen $y$ for the name 'tetrataenia'. In 1995, B\&R's inspection of type specimen $x$ (and of its accompanying documentation) revealed that it must have originally been collected from a location more to the west (as indicated by the arrow), causing $x$ to fall within the range of the peninsular subspecies; (c) Upon B\&R's discovery that type specimen $x$ had originally been collected from a population of the peninsular subspecies, they renamed that subspecies into 'infernalis,' in accordance with Art. 23. Following Art. 61, they proposed a new name ('concinnus') for the coastal subspecies; (d) In 2000, the Commission baptized specimen $z$ as the new namebearer (the neotype) for 'infernalis' and simultaneously stripped specimen $x$ from its role as name-bearer.

preparation for a systematic review of the genus of Garter Snakes (Rossman, Ford, and Seigel, 1996), they decided to check up on the type specimens that anchored the subspecies names 'infernalis' and 'tetrataenia'. Much to everyone's surprise, they found that the type specimen for 'infernalis' (a specimen that had been deposited in the Muséum national d'Histoire naturelle, in Paris, in 1835) must have originally been collected from a site within the range of the subspecies known by the name of 'tetrataenia' in 1995 (Figure 11b).

Haber points out that the International Code of Zoological Nomenclature (hereafter: the Code) prescribes what needs to be done in a situation like this. Following its 'Principle of Typification' (Article 61) a new name and type specimen would need to be coined for the coastal subspecies, for which the name 'infernalis' had thus far been used incorrectly. As for the peninsular subspecies, the 'Principle of Priority' (Article 23) would need to be invoked to determine its correct name. This principle states that the oldest name applicable to a taxon by means of a type specimen is its only valid name, and requires that all other applicable names become suppressed synonyms. 
Hence, whenever two or more type specimens are judged to belong to the same taxon, Art. 23 mandates that all type specimens but the most 'senior' one need to be demoted; they become 'junior types' carrying 'junior synonyms'.

B\&R duly followed the procedure just described and applied Arts. 61 and 23 accordingly (Boundy and Rossman, 1995). They assigned a new name and type specimen to the coastal subspecies taxon and they determined that the name 'infernalis' was the valid name of the peninsular subspecies, since it had been coined some 40 years before 'tetrataenia'. 2. The Paris specimen, carrying the name 'infernalis,' thus became the senior type specimen of the subspecies on the San Francisco peninsula (Figure 1 1 ).

Importantly, Haber stresses that none of the events and procedures described up to this point amount to a misidentification of a type specimen. B\&R did not discover that the type specimen for 'infernalis' failed to belong to the taxon designated by this name. They only determined that taxonomists had been seriously mistaken about which taxon out in the world was the taxon this type specimen actually belonged to, and thus anchored the name of. Haber also points out that no misidentification of a type specimen occurred when the type specimen for 'tetrataenia' got demoted to junior status (by applying Art. 23). This type specimen continued to belong to the subspecies it named. The name for this subspecies had merely become a (silenced) synonym of 'infernalis' (Haber, 2012, p. 775) $3^{3}$

The case only gets interesting from a philosophical viewpoint when we turn to the events that followed. In 1997, taxonomists Barry and Jennings (hereafter: B\&J) pointed out that the nomenclatural consequences of B\&R's discovery were very unfortunate. They drew attention to the fact that the name 'tetrataenia' was widely known outside taxonomic circles as the name for the endangered subspecies on the San Francisco peninsula. To suppress this name, and to start referring to the peninsular subspecies as 'infernalis,' would be pervasively confusing to government officials and NGO workers. B\&J suggested that the taxonomic community avoid this undesirable situation by submitting a petition to the International Commission on Zoological Nomenclature (hereafter: the Commission) (Barry and Jennings, 1998). They requested the Commission to overrule the 'default' procedure of applying Arts. 23 and 61 by appealing to Art. 75.6 of the Code:

\footnotetext{
${ }^{2}$ The name 'infernalis' was coined by Blainville (1835) and the name 'tetrataenia' by Cope in Yarrow (1875).

${ }^{3} \mathrm{~A}$ silenced name can be reactivated in the future. A change in judgment about taxon boundaries could leave the type specimens for 'tetrataenia' and 'infernalis' in separate taxa again, allowing the type specimen for 'tetrataenia' to return to senior status.
} 
Article 75.6: Conservation of prevailing usage by a neotype. When an author discovers that the existing name-bearing type of a nominal species-group taxon is not in taxonomic accord with the prevailing usage of names and stability or universality is threatened thereby, he or she should maintain prevailing usage [Art. 82] and request the Commission to set aside under its plenary power [Art. 81] the existing name-bearing type and designate a neotype.

On the basis of Art. 75.6, B\&J requested the Commission to turn the Paris specimen that served as name-bearer for 'infernalis' into a regular (non-type) specimen, and to baptize a different specimen from within the range of the coastal subspecies as the new name-bearer (the 'neotype') for 'infernalis'. If the Commission were to vote in favor of this petition, the name 'tetrataenia' would regain senior status, and be restored as the valid name for the endangered subspecies on the San Francisco peninsula.

In line with standard procedures, B\&J's petition was published (as Case 3012) and a call for comments was issued to the taxonomic community. Approving comments were received, and in the year 2000 the Commission voted in favor of Case 3012 (ICZN, 2000). The Paris specimen that anchored 'infernalis' was stripped of its status as name-bearer, and a specimen from within the range of the coastal subspecies was selected to serve as the new type specimen for 'infernalis'. As a result, the type specimen for 'tetrataenia' regained senior status, the pre-1995 usage of 'tetrataenia' and 'infernalis' was restored, and unnecessary confusion among conservationists got nipped in the bud (Figure $1 \mathrm{~d}$ ).

Haber argues that this decision by the Commission entails that a type specimen got misidentified. The Commission's ruling on the basis of Art. 75.6 shows "that the identity conditions of type specimens and their designated species can come apart; the belongs to relation is contingent, and de dicto necessity fails." This has philosophically significant consequences: "[It] presents a serious challenge to philosophical accounts of [taxon] names" and "suggests that rigid designation and causal theory of reference may be more fragile than supposed." (Haber, 2012, p. 786).

\section{Contingency confusion}

On first inspection, it may seem that the writings of Levine, LaPorte and Haber have delivered us, step-by-step, a refined picture of the philosophical foundations of the type method. Levine raised an interesting issue about the type method that LaPorte showed could be resolved by appealing to modal logic. Haber then showed that the intricacies of taxonomic practice again change the face of the type method. In this Section, I will argue that a closer look at the arguments that have been offered undercuts this surface 
impression. I will begin by examining LaPorte's purported dissolution of Levine's paradox (Section 3.1), and will move on to take a second look at the paradox itself (Section 3.2). I will conclude by assessing Haber's argument (Section 3.3).

\subsection{Modal contingency?}

We have seen that LaPorte argued that Levine's paradox disappears when we distinguish between de dicto and the de re modalities of necessity and contingency. In this Section, I will take a closer look at LaPorte's contention that the relation between a type specimen and its species is contingent de re. ${ }^{4}$ Let me begin by quoting LaPorte on this point:

The de re sentence "Any species with a type specimen necessarily contains its type specimen" is true if and only if any species with a type specimen in the actual world contains that very type specimen in every possible world. This reading does not seem to be true. [Assume that] Rover serves as a type specimen for Canis familiaris in the actual world but [that] there are worlds in which he is not in Canis familiaris, never having been born. It is contingent, not necessary, that Canis familiaris contains Rover.

$$
\text { (LaPorte, 2003, p. 587) }
$$

Figure 2 is a diagrammatic representation of the situation LaPorte sketches. The left side represents the state of affairs in the actual world, W1. In this world, a specimen $x$ (Rover) has been selected to serve as name-bearer for the taxon name ' $S$,' which designates the taxon that $x$ belongs to: taxon $S$. The right side represents a possible world, W2, in which taxon $S$ exists, but in which specimen $x$ was never born. In this world specimen $y$ serves as name-bearer for ' $S$ '.

LaPorte argues that a setup like this proves the falsity of the de re sentence "Any species with a type specimen necessarily contains its type specimen." Yet, Figure 2 helps us see that LaPorte gets it wrong.

Notice, first, that W1 and W2 are both worlds in which taxon $S$ is a taxon with a type specimen. In either world, taxon $S$ is designated by a name that is anchored to a name-bearer. Next, note that $S$ contains the type specimen it has in either possible world, by virtue of a belongs to relation obtaining between $S$ 's name-bearing specimen and $S$ itself. Thus, it appears that in all possible worlds in which we find a species with a type specimen, it contains its type specimen. This means that the de re sentence "Any species with a type specimen necessarily contains its type specimen" is true after all.

\footnotetext{
${ }^{4}$ I will zoom in on de dicto necessity when discussing Haber's argument.
} 


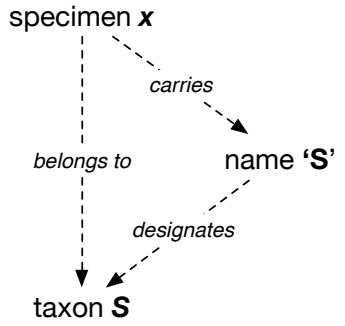

W1

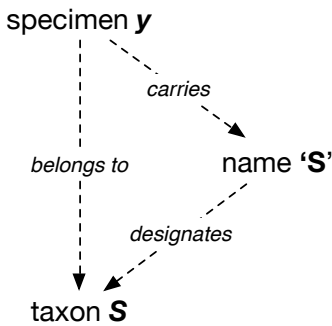

W2

Figure 2: Modal contingency? Specimen $x$ (Rover), which has been baptized as the name-bearer for the name ' $\mathrm{S}$ ' ('Canis familiaris') in the actual world, W1, carries that name for the taxon it belongs to: taxon $S$ (Canis familiaris). There are, however, possible worlds in which specimen $x$ has never been born, but in which taxon $S$ does exist. W2 is one of those possible worlds. In that world $S$ contains another specimen $y$ as its type specimen.

How, then, can LaPorte arrive at the opposite conclusion? The reason is that he takes an erroneous approach to evaluating the truth value of the de re sentence. We have seen that, according to LaPorte, this sentence is true "if and only if any species with a type specimen in the actual world contains that very type specimen in every possible world." (LaPorte, 2003, p. 587). Surely, this is false. For the de re sentence to come out true, it is not required that the very type specimen from the actual world needs to be the type specimen in all possible worlds. In other words, it is not required that 'type specimen of $S^{\prime}$ rigidly designates a token specimen. It is merely required that in any possible world in which a species $S$ has $a$ specimen that serves as its type specimen, that specimen belongs to $S$.

Because of the approach LaPorte takes, he ends up evaluating the subtly (but substantially) different de re sentence "Any species with a specimen $x$ as its type specimen necessarily contains that very specimen $x$ as its type specimen." This sentence is indeed false. It is a contingent fact that the specimen $x$ that actually serves as the type specimen of $S$ serves as its type specimen in all possible worlds. There are possible worlds in which another specimen $y$ was selected to serve as $S^{\prime}$ s type specimen. ${ }^{5}$ But this only shows that what makes a specimen a type specimen is (quite obviously) contingent on our choice of which specimen to baptize with a taxon name. It does not show that a species with a type specimen contains its type specimen contingently.

\footnotetext{
${ }^{5}$ There are in fact many more possible worlds for which this holds than LaPorte appears to realize. It not only holds for those worlds in which $x$ was never born, but also for worlds in which another specimen $y$ of $S$ was discovered first.
} 
It thus appears that LaPorte fails to dissolve Levine's paradox. He does not show how a species with a type specimen can contain its type specimen of necessity and contingently. If anything, LaPorte's distinction between modalities enables us to see that type specimens belong to their species with de dicto necessity and with de re necessity.

There is, however, a further complication. For, even if we correct LaPorte's argument, it still fails to address the paradox Levine raised. The reason is that Levine's worries are not addressed by distinguishing between modalities. A closer look at Levines article reveals that he was not concerned with a form of modal contingency in the relation between type specimens and their species, but rather with a form of temporal contingency.

\subsection{Temporal contingency?}

A close reading of Levine's article reveals that he considers the species-asindividuals thesis to entail two relations of contingency between a species and its specimens. First, it entails that a species $S$ would still be species $S$ if an organism $o$ that it actually contains had never been born. In other words: "having $o$ as a member isn't constitutive of S's identity" (Levine, 2001, p. 333). Levine notes that this is a familiar consequence, which has been noted by many philosophers. It is, indeed, what LaPorte considers the contingency thesis to be all about: the view that $S$ contains $o$ contingently de re.

Yet, surprisingly, Levine's actual concerns about contingency do not derive from this first entailment of the species-as-individuals thesis, but from a second one, namely, "that being part of $S$ isn't constitutive of $o$ 's identity." Levine notes that this consequence "may not be obvious," but he argues that it is true nonetheless (ibid., p. 333; italics in original).

He takes this second consequence to follow from the fact that speciesindividuals, by virtue of being biological individuals, must be able to exchange parts. Just like familiar biological individuals such as multicellular organisms can lose parts to other individuals (e.g. by transplantation), so must species-individuals be capable of losing their parts to other speciesindividuals. An organism $o$ that belongs to a species $S$ at $\mathrm{t}=0$ may end up belonging to another species $T$ at $t=1$. Hence, in Levine's view, the relation between an organism and the species it belongs to is temporally contingent.

Levine goes on to note that this notion of temporal contingency is incompatible with the designation thesis. To see why this is so, he asks us to first consider the (unproblematic) case of naming organism-individuals, for which we do not use the type method.

Suppose Aristotle is named 'Aristotle' in virtue of the coupling of his father's first utterance of the name, together with his ostensive contact with the boy's left ear. . . Should Aristotle lose his left ear while listening for the music of the spheres, he is no less Aristotle 
for the loss, nor any less the proper referent of the name 'Aristotle.' Finally, matters aren't changed in the slightest if we imagine the ear to have been stolen by a Platonist cabal, and grafted to the head of academician Speusippus. The name doesn't follow the ear.

$$
\text { (Levine, 2001, p. 335) }
$$

Now, compare this to the way we name species-individuals using the type method. On the one hand, the designation thesis tells us that the reference of a taxon name is fixed by its 'ear', its type specimen, which cannot possibly transfer to a different species. One the other hand, temporal contingency tells us that any specimen (the type specimen included) can transfer to a different species. Hence, we are stuck with a paradox. The designation thesis and the contingency thesis cannot both be true.

This paradox is not lifted by modal or semantic considerations. Levine's worries instead arise from what he takes to be a fundamental metaphysical truth about individuals: the fact that they can exchange parts with other individuals of the same kind.

However, this metaphysical consideration is itself false. Contrary to what Levine thinks, the species-as-individuals thesis does not entail temporal contingency in the relation between type specimens and their species. Levine errs in thinking that there is a strict analogy between species-individuals and organism-individuals, and thereby misjudges that part-transfer is possible in either case. In reality, the definition of part-hood for species-parts does not allow for the transfer of parts between species. For an organism $o$ to be part of a species-individual $S$, it is necessary for $o$ to stand in a certain genealogical relation to other parts of $S$ and their common ancestor(s). Organs can be transplanted from one organism to another, but specimens cannot move from one species to another. Once an organism is born in a certain species, it stays in that species.

This metaphysical 'restriction' means that Levine's reading of the contingency thesis fails to go through, and that no paradox emerges. Indeed, correcting Levine's error makes us realize that the type method works exactly because species (like other biological taxa) cannot lose their name-bearing parts to other species (or other taxa) ${ }^{6}$

\footnotetext{
${ }^{6}$ Interestingly, LaPorte briefly notes at the outset of his article that "Levine (2001, p. 335) thinks that [it] follows from species' being individuals . . . [that] individuals can lose parts, and [that] those parts can become parts of other individuals." This shows that LaPorte is aware that Levine was worried about temporal contingency. LaPorte also observes that this worry may not be warranted: "It is not clear to me that just any individual's parts could become parts of another individual." However, LaPorte surprisingly fails to follow this thought through to its conclusion, thereby showing that Levine's paradox does not arise. Instead, he abandons the discussion of temporal contingency and starts developing
} 
We can conclude, then, that the accounts of Levine and LaPorte both fail. Neither of their arguments to the effect that the relation between type specimens and their species is contingent holds water. Contra LaPorte, a species cannot have a type specimen in some world without containing it in that world. Contra Levine, a species cannot lose its type specimen to another species. 7

\subsection{The Garter snake that bites its own tail}

Since Haber's argument does not turn on issues about temporal or de re contingency, it calls for an independent assessment. As we have seen in Section 2.3. Haber argues that application of Art. 75.6 from the Code shows that the relation between type specimens and their species is de dicto contingent. He therefore concludes that the de dicto sentence "Necessarily, any species with a type specimen contains its type specimen" is false, and that taxon names fail to designate rigidly. 8

To determine whether Haber is right, let us begin by taking a closer look at his rendition of what happens when Art. 75.6 is applied. According to Haber, it entails that "a new type (i.e., a neotype) is designated, and the old one [is] no longer recognized as belonging to the species it designated." Or, as he puts it a little later: "[The type specimen] is reassigned to a new species, and no longer belongs to the species it formerly designated." (Haber, 2012. pp. 775,779$)$.

We should immediately pause here, since this interpretation presages two major problems.$^{9}$ First, if Haber's interpretation is correct, it fails to support his own argument that de dicto necessity is hereby falsified. To falsify de dicto necessity, it is not sufficient for a type specimen to fail to belong to

his argument about modal contingency, which he claims is "enough to generate the paradox" (LaPorte, 2003. p. 584; italics mine). This is a critical error. The (apparent) paradox that LaPorte goes on to discuss is not Levine's paradox.

${ }^{7}$ Levine makes other errors that I will not discuss here. Let me just note that he may have also misunderstood the real force of the designation thesis. This much is suggested by his claim that "the species membership of a type specimen [can be] reassigned" in a revision of taxonomic boundaries (Levine, 2001. p. 334). Haber similarly observes that that this claim "carries unwarranted modal force, and is incorrect." Haber (2012, p. 773).

${ }^{8}$ It appears, though, that Haber is actually aiming to show the falsity of the more general de dicto sentence "Necessarily, any taxon with a type specimen contains its type specimen." This is suggested by the fact that he roots his argument in case study of subspecies, from which he then infers conclusions about species without further explanation.

${ }^{9}$ And two minor, terminological ones: First, it is a bit odd to state that type specimens designate taxa. Type specimens merely bear taxon names that designate taxa. Secondly, Case 3012 (on which Haber bases his analysis of Art. 75.6) concerns type specimens of subspecies, not species (see footnote 8 ). 
the taxon for which it formerly served as name-bearer. Instead, it must be possible for a type specimen to fail to belong to the taxon for which it actually serves as name-bearer. Figure $3 \mathrm{~b}$ drives this point home. It depicts a taxon $S$ with a type specimen by virtue of there being a specimen that bears the name ' $S$ ' designating $S$. But $S$ does not contain its type specimen, since there is no belongs to relation connecting type specimen for ' $S$ ' to species $S$. This situation clearly falsifies de dicto necessity; the belongs to and designates arrows point to different taxa. But it is not the situation Haber describes as being brought about by applying Art. 75.6. On Haber's interpretation, the carries and designates arrows are cancelled altogether.

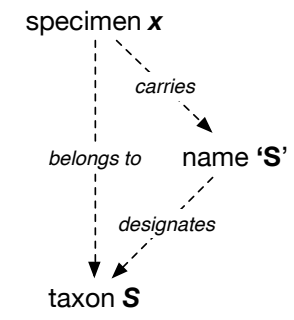

a
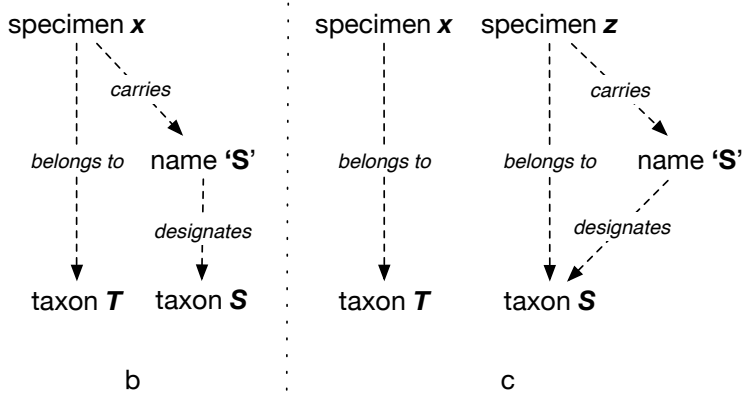

Figure 3: (a) A taxon $S$ (infernalis) with a type specimen $x$ (the Paris specimen) contains its type specimen; (b) A taxon $S$ with a type specimen that fails to contain its type specimen. If this situation can obtain, it falsifies the de dicto sentence "Necessarily, any taxon with a type specimen contains its type specimen"; (c) The situation that actually obtains when Art. 75.6 is applied. The selection of a neotype specimen $z$ from a different taxon than the old type specimen $x$ causes the latter specimen to stop belonging to the taxon it formerly designated. This result does not violate de dicto necessity, since the belongs to and designates arrows do not come apart.

This get us to a second error with Haber's interpretation: it is descriptively inaccurate. It is not the case that when Art. 75.6 gets applied, a type specimen starts belonging to a different taxon than that for which it formerly served as name-bearer. To argue that a type specimen can fail to serve as name-bearer is to misunderstand what a type specimen is; 'type specimen' is defined as 'name-bearing specimen'. What Haber should have said, is that application of Art. 75.6 causes a specimen that formerly served as type specimen to stop belonging to the taxon for which it formerly anchored the taxon name.

Only this interpretation accounts for what happened in Case 3012, when Art. 75.6 was applied. Until the year 2000, the Paris specimen $x$ served as the name-bearer for 'infernalis,' and thus served as infernalis' type specimen (Figure 3a). When, in 2000, the Commission assigned the neotype specimen $z$ for this name, it thereby stripped specimen $x$ of its function as name-bearer for 'infernalis.' And because specimen $z$ was intentionally selected from a different taxon, it meant that specimen $x$ stopped belonging to the infernalis taxon. Thus, application of Art. 75.6 turned specimen $x$ into a non-type 
specimen that no longer belonged to the taxon for which it formerly served as name-bearer (Figure 3k).

In summary, application of Art. 75.6 effects a change from the situation in Figure $3 \mathrm{a}$ to the situation in Figure $3 \mathrm{k}$. Art. 75.6 does not effect a shift from the situation in Figure $3 \mathrm{a}$ to that in Figure $3 \mathrm{~b}$, and therefore does not show that de dicto necessity fails.

This leaves us with the question whether it is possible in principle to arrive at the situation depicted in Figure $3 \mathrm{p}$. Could it be that Haber was wrong about Art. 75.6, but right about the general case? It is possible for a type specimen to belong to one taxon while carrying the name for another taxon? The answer has to be 'no'. If we baptize a specimen that belongs to some taxon as name-bearer, we thereby fix the name's reference to the taxon the specimen belongs to. Practical errors and complications cannot get between this. We simply cannot discover that the name carried by a type specimen designates a different taxon than that which the type specimen belongs to. If we know that a type specimen belongs to a taxon, we know with certainty that it carries the name of that taxon. ${ }^{10}$ In other words, to recognize what the type method is, is to recognize the truth of de dicto necessity.

If this is right, then Haber was wrong to argue that taxonomic practice presents "a serious challenge" to philosophical accounts of naming, or to their applicability to taxonomy. Neither Case 3012 nor any other case study will show that de dicto necessity fails, and therefore won't threaten rigid designation of taxon names that are anchored to type specimens.

This is not to say that nothing can be learned from Case 3012, or from the intricacies of taxonomic practice more generally. On the contrary, Haber's call for attending to the deployment of the type method in actual taxonomic practice needs to be heard, albeit not for the reasons he considered. Instead of showing that the type method encounters complications or can break down, the intricacies of taxonomic practice should make us wonder how the type method is made to work in the face of frequent error and ambiguity.

\section{Types, errors, and rules}

In this Section, I will argue that the real significance of Case 3012, and of case studies in taxonomic naming more generally, is that they reveal how the type method is insulated from the inevitable errors that crop up in taxonomic practice. The type method is protected from breaking down in practice through its embedding in codes of nomenclature, which scaffold its deployment in various ways.

\footnotetext{
${ }^{10}$ This holds even if the name is suppressed in practice, when it is a junior synonym (see page 7).
} 
Let us first take another look at Case 3012 in order to appreciate how Art. 75.6 serves to support the type method, instead of derail it. For a start, reconsider B\&R's discovery from 1995 by asking what they found out about the infernalis type specimen. The only correct answer is that B\&R discovered that taxonomists had been wrong about which taxon was its taxon. Although taxonomists had always known (with a priori certainty) that the infernalis type specimen belonged to the infernalis taxon, they had failed to pinpoint this taxon 'out there' in California. Therefore, they had misapplied the name 'infernalis.'

In itself, an error of this kind is hardly remarkable. It merely illustrates a central tennet of the causal theory: we can know the referent of a name while failing to define it. What makes Case 3012 noteworthy, though, is that it reveals that only professional taxonomists recognized, on this basis, that an error had occurred. The folk, on the other hand, were perplexed that taxonomists considered some minor datum about an obscure specimen in a Paris museum to have major consequences for the naming of Californian garter snakes. In the perception of the folk, the names 'infernalis' and 'tetrataenia' were defined as the coastal taxon and the peninsular taxon, respectively. Hence, Case 3012 reveals that the folk do not always follow the causal-theoretical scheme for taxonomic naming that professional taxonomists use. In this case, they applied taxon names on a descriptivist basis.

This confronted expert taxonomists with a dilemma. They would either have to convince the folk to amend their widespread (but by expert standards, incorrect) usage of 'infernalis' and 'tetrataenia,' or expert taxonomists would have to change their own naming scheme.

Against this background we can start to appreciate the purpose Art. 75.6 serves. In circumstances like the above, this article enables expert taxonomists to continue to use the type method without getting massively out of step with the folk's usage of names. We have already seen that Art 75.6 effects this by allowing an existing name to become attached to a new type specimen. If there had not been an option to redesignate a type specimen in this manner, there would have been no easy way out of the dilemma presented by Case 3012. Professional taxonomists would have either had to face the uphill challenge of convincing the folk to change their usage of taxon names, or, in the most extreme case, they would have had to (locally) drop the type method. By removing the latter threat, Art. 75.6 shows how taxonomic naming is insured against getting out of step with the causal theory.

Looking beyond Case 3012, we find that Art. 75.6 is not the only one of its kind. All nomenclatural codes that incorporate the type method contain articles that scaffold its deployment in the face of the hurdles posed 
by taxonomic practice ${ }^{11}$ Many of these articles deal with the background conditions necessary for making the type method work. For example, all codes include recommendations about storing, preserving, labeling and accessing type specimens that are needed to get the type method off the ground. If taxonomists would designate type specimens without marking and preserving them, the whole point of having these reference standards would be subverted. The same would follow if all type specimens were kept in private collections, unaccessible for study by experts. The (Zoological) Code emphasizes these matters on a general level, by stressing "[the] value of name-bearing types ... They are international standards of reference that provide objectivity in zoological nomenclature and must be cared for as such. They are to be held in trust for science by the persons responsible for their safe keeping." (ICZN, Art. 72.10). In this sense a type specimen is not much different from other archived reference standards, like the International Prototype Kilogram. This object similarly needs to be preserved and stored securely to serve its standardizing function.

Yet, even if type specimens are cared for, they will not last forever. They often perish, and are sometimes lost. In such cases taxonomists can select (or, depending on the situation, must request a commission to select) a neotype for the existing name. Some codes even specify what to do if a former type specimen that was deemed lost is found again. It may automatically become re-established as type (BioCode, Art. 16.3; ICN, Art. 9.6; ICZN, Art 75.8), or a nomenclatural commission will have to make a decision about this (ICNB, Art. 18e).

These slight differences between nomenclatural codes illustrate that the type method is supported in subtly different ways in different domains. But none of these differences eat away at the logical skeleton of the type method; all these codes are based on the principle that when a name is anchored to a type specimen, it designates the taxon to which the type specimen belongs. The differences between codes are of a procedural kind: they are variations in ways of ensuring that the type method can continue to be followed when it has become difficult to apply it in practice.

However, it may not be so clear that this skeleton still remains erect when we turn to yet another class of articles. Thus far, we have assumed that name-bearers are single specimens. But this is not required in all domains. In paleontology, for example, it is permitted to elect a natural impression,

\footnotetext{
${ }^{11}$ Among the other type-based codes are the International Code of Nomenclature for Algae, Fungi, and Plants (ICN) (McNeill et al., 2012), the International Code of Nomenclature of Bacteria (ICNB) (Lapage et al., 1992), and the draft BioCode (Greuter et al., 2011), an ongoing attempt to unify domain-specific codes.
} 
mould, or cast of a fossil as type (ICZN, Art. 72.5.3). In botany, an illustration of a single specimen may count as a type. In yet other domains, taxonomists are forced to designate groups of organisms as types, because a single one would be too fragile, incomplete or small to serve as type. Hence, taxonomists select as types colonies of cnidarians, strains from pure cultures of bacteria, and individuals representing stages in the life cycle of protistans (ICZN, Arts. 72.5.4, 72.5.5; ICNB, Rule 18a). This not only shows that the type method is in some sense 'broader' than was considered earlier, but it also opens up an obvious new avenue for error: it may turn out that a type belongs to different taxa.12 In fact, an error of this kind can even occur when a taxonomist thinks he has baptized a single specimen as type, but turns out to have named a collection of body parts from different taxa. This happens not seldomly in paleontology 13

These cases could be said to undermine the picture of the type method I outlined earlier, yet they only do so trivially. In assessing contingency debate, I did not question the assumption (signed up to, implicitly, by Levine, LaPorte, and Haber) that when taxonomists baptize a type, they baptize a sample that belongs to one taxon only. But if we let go of that assumption, and make the requisite modifications to the de dicto and de re sentences discussed earlier, we arrive at the same conclusion: it is necessary (de dicto and $d e r e$ ) that any name-bearing sample (partially) designates all the taxa it (partially) belongs to.

However, it would be more plausible to argue something else has happened when we find that a type belongs to more than one taxon. We should rather admit that the original namer has failed to designate a type for the name he coined. This, indeed, is what the nomenclatural codes tell us to conclude. All codes specify that when a (purported) type is found to contain material from different taxa, the original type designation is determined to have failed. To successfully anchor the name to a type, components then need to be removed from the original sample until it contains material from one named taxon only (e.g. ICZN, Art. 73.1.5; ICN, Art. 9.14). In other words, whether a baptism of a type succeeds is contingent on sound judgment. But when it succeeds, it thereby becomes necessary that the type belongs to its taxon. Again, this shows that although contingency in taxonomy runs deep, it never touches the logical core of the type method.

\footnotetext{
${ }^{12}$ Note that this is only an error from the viewpoint of taxonomic naming. Biologists do name 'organisms' that belong to more than one taxon, like lichen - associations of a fungus with a photosynthetic partner. But these symbionts have no taxonomic status; they are only understood as 'growth forms'. (In practice, taxonomists refer to lichen by the fungal component. See ICN Art. 13d and Jørgensen (1998).)

${ }^{13}$ I thank Kim Sterelny for pointing this out.
} 


\section{Conclusion}

The contingency debate arose from a blend of misconceptions about the type method and misunderstandings of each others' positions. Contrary to what Levine, LaPorte, and Haber argued, there is no sense in which type specimens belong only contingently to their species. Types belong to their species out of necessity.

To recognize this point is not to deny that applying the type method is surrounded by a lot of contingency in practice. Haber was right to draw attention to the role of contingency on the practical side of naming, but for the wrong reasons. Drawing on his lead, I have shown that lots of things can go wrong in the preservation, selection, and application of types. Codes of taxonomic nomenclature attempt to minimize and adjudicate error on all these practical matters. In doing so, they do not undercut the type method, but they scaffold it. Nomenclatural codes protect the type method from being abandoned under the weight of the ambiguities and errors that will inevitably crop up in taxonomic practice.

\section{References}

Barry, S. J. and M. R. Jennings (1998). Coluber infernalis Blainville, 1835 and Eutaenia sirtalis tetrataenia Cope In Yarrow, 1875 (currently Thamnophis sirtalis infernalis and T. s. tetrataenia; reptilia, squamata): proposed conservation of the subspecific names by the designation of a neotype for T. s. infernalis. Bulletin of Zoological Nomenclature, 55(4), pp. 224-228.

Blainville, M.-H. D. de (1835). Description de quelques espèces de reptiles de la Californie, précédée de l'analyse d'un system général d'erpétologie et d'amphibiologie. Nouvelles Annales du Museum d'Histoire Naturelle, Paris, 3(4), pp. 233-296.

Bolton, C. J. (1996). Proper names, taxonomic names and necessity. The Philosophical Quarterly, 46(183), pp. 145-157.

Boundy, J. and D. A. Rossman (1995). Allocation and status of the garter snake names Coluber infernalis Blainville, Eutaenia sirtalis tetrataenia Cope and Eutaenia imperialis Coues and Yarrow. Copeia, 1995(1), pp. 236-240.

Ereshefsky, M. (2004). The Poverty of the Linnaean Hierarchy: A Philosophical Study of Biological Taxonomy. Cambridge, UK: Cambridge University Press, pp. 1-328.

- (2007). Foundational issues concerning taxa and taxon names. Systematic biology, 56(2), pp. 295-301. 
Greuter, W et al. (2011). Draft BioCode (2011): Principles and rules regulating the naming of organisms. Taxon, 60(1), pp. 201-212.

Haber, M. H. (2012). How to misidentify a type specimen. Biology and Philosophy, 27(6), pp. 767-784.

Hull, D. L. (1976). Are species really individuals? Systematic Zoology, 25(2), pp. 174-191.

- (1982). Exemplars and scientific change. PSA: Proceedings of the Biennial Meeting of the Philosophy of Science Association, 2, pp. 479-503.

- (1988). Science as a Process. Chicago: The University of Chicago Press.

International Commission on Zoological Nomenclature (2000). Opinion 1961: Coluber infernalis Blainville, 1835 and Eutaenia sirtalis tetrataenia Cope in Yarrow, 1875 (currently Thamnophis sirtalis infernalis and T. s. tetrataenia; reptilia, serpentes): subspecific names conserved by the designation of a neotype for T. s. infernalis. Bulletin of Zoological Nomenclature, 57(3), pp. 191-192.

Jørgensen, P. M. (1998). What shall we do with the blue-green counterparts? The Lichenologist, 30(4-5), pp. 351-356.

Kripke, S. A. (1980). Naming and Necessity. Cambridge, MA: Harvard University Press.

LaPorte, J. (2003). Does a type specimen necessarily or contingently belong to its species? Biology and Philosophy, 18(4), pp. 583-588.

Lapage, S. P., P. H. A. Sneath, E. F. Lessel, V. B. D. Skerman, H. P. R. Seeliger, and W. A. Clark, eds. (1992). International Code of Nomenclature of Bacteria. Washington: ASM Press.

Levine, A (2001). Individualism, type specimens, and the scrutability of species membership. Biology and Philosophy, 16(3), pp. 325-338.

Mayr, E. (1989). Attaching names to objects. In: What the Philosophy of Biology is. Ed. by M. Ruse. Dordrecht: Kluwer Academic Publishers, pp. 235-243.

McNeill, J et al., eds. (2012). International Code of Nomenclature for Algae, Fungi, and Plants (Melbourne Code). Koeltz Scientific Books. URL: http : //www . iapt-taxon.org/nomen/main.php.

Putnam, H. (1975). The meaning of "meaning". In: Language, Mind and Knowledge. Ed. by K Gunderson. Minnesota Studies in the Philosophy of Science VII. Minneapolis, MN: University of Minnesota Press, pp. 131-193.

Rossman, D. A., N. B. Ford, and R. A. Seigel (1996). The Garter Snakes: Evolution and Ecology. Norman, OK: University of Oklahoma Press.

Stanford, P. K. and P. Kitcher (2000). Refining the causal theory of reference for natural kind terms. Philosophical Studies, 97(1), pp. 99-129. 
Whewell, W. (1840). The Philosophy of the Inductive Sciences: Founded upon their History (2 Vols). Vol. 1. London: John W Parker.

Witteveen, J. (in progress). Suppressing synonymy with a homonym: the emergence of the nomenclatural type concept in nineteenth century natural history.

Yarrow, H. C. (1875). Report upon the collections of batrachians and reptiles made in portions of Nevada, Utah, California, Colorado, New Mexico, and Arizona, during the years 1871, 1872, 1873 and 1874. In: Report upon Geographical and Geological Explorations and Surveys West of the 100th Meridian. Vol. 5 (Zoology). part 4. Washington: Government Printing Office, pp. 509-584. 